\title{
EL PROTOCOLO DE MADRID Y EL RÉGIMEN DE LAS FRANQUICIAS EN COLOMBIA
}

\section{Rodrigo Plazas*}

Fecha de recibido: 8 de marzo de 2013

Fecha de aprobado: 5 de mayo de 2013

Artículo de reflexión

Forma de citación: Plazas, R. A. (2013). El Protocolo de Madrid y el régimen de las franquicias en Colombia. Revista Prolegómenos. Derechos y Valores, 16, 31, 155-172.

\section{Resumen}

El estudio que se presenta a continuación hace parte del proyecto de investigación El Protocolo de Madrid como elemento dinamizador de las franquicias en Colombia, siendo en esencia un avance parcial que tiene por objetivo establecer los elementos teóricos sustanciales del Protocolo de Madrid, así mismo su aplicación sobre la normatividad referente a las marcas, registro marcario y las franquicias.

Este artículo hace un análisis sobre los elementos que hacen posible la relevancia jurídica del Protocolo de Madrid. En las marcas se destacan los aspectos constitutivos y su desarrollo histórico. Finalmente, se hace un análisis sobre la franquicia como dinamizador de las relaciones comerciales en las actuales condiciones creadas por el desarrollo tecnológico.

\section{Palabras clave}

Propiedad industrial, Marcas, Protocolo de Madrid, Franquicia

\section{THE MADRID PROTOCOL AND THE FRANCHISE REGIME IN COLOMBIA}

\begin{abstract}
The following study is part of the research project The Madrid Protocol as a stimulating element for franchises in Colombia; a preliminary document that aims to elucidate the main theoretical aspects of the Madrid Protocol, and its applications regarding trademarks, trademark law, trademark registration and franchises.
\end{abstract}

* Abogado de la Universidad Sergio Arboleda, Magister en Derecho Privado de la Universidad Sergio Arboleda, estudiante de Doctorado en Derecho de la Universidad de Buenos Aires. Docente investigador del Grupo de Derecho Económico y Estado de la Corporación Universitaria Republicana. Correo electrónico: rodrigoplazas@urepublicana.edu.co, roplazz@ me.com. 
This article analyzes the elements that make possible the legal significance of the Madrid Protocol. In trademarks, it highlights its constitutive elements and their historic development. Finally, it analyzes the role of the franchise as a driving force for trade relations under the current conditions created by technological development.

\section{Key words}

Industrial Property, Trademarks, The Madrid Protocol, Franchise

\section{O PROTOCOLO DE MADRI E DO REGIME DAS FRANQUIAS NA COLÔMBIA}

\section{Resumo}

O estudo apresentado a seguir é parte do projeto de pesquisa O Protocolo de Madri como um elemento dinamizador das franquias na Colômbia, sendo, em essência, uma antecipação parcial que tem por objetivo estabelecer os elementos teóricos importantes do Protocolo de Madri, assim mesmo a sua aplicação sobre a normatividade relativa às marcas, registro de marca e das franquias.

Este artigo faz uma análise sobre as condições que torna possível a relevância jurídica do Protocolo de Madri. Nas marcas destacam-se os aspectos constitutivos e seu desenvolvimento histórico. Finalmente, é feita uma análise sobre a franquia como um dinamizador para as relações comerciais nas condições atuais criados pelo desenvolvimento tecnológico.

\section{Palavras-chave}

Propriedade intelectual, Marcas, Protocolo de Madri, Franquia.

\section{PREGUNTA DE INVESTIGACIÓN Y METODOLOGÍA DEL PROYECTO DE INVESTIGACIÓN}

El presente trabajo hace parte del proyecto de investigación titulado El Protocolo de Madrid como elemento dinamizador de las franquicias en Colombia, y atañe a un avance parcial, comprendido principalmente por el marco teórico del estudio. Se precisa inicialmente cómo el objetivo general del proyecto consiste en establecer cuál es la incidencia o impacto jurídico en las empresas que tiene la adhesión de Colombia al Protocolo de Madrid, como parte vital y eficiente de las franquicias, de ahí que la pregunta de investigación busca establecer ¿cuál es la incidencia del Protocolo de Madrid como elemento dinamizador de las franquicias en Colombia?
De este objetivo se pretenden desarrollar otros más específicos, como analizar los elementos relevantes del Protocolo de Madrid frente a la actual legislación colombiana en relación con el registro marcario y la propiedad industrial, y establecer el nivel de protección que adquieren las marcas con la adhesión de Colombia al Protocolo de Madrid.

Definidos los objetivos del proyecto, a continuación se precisa la metodología utilizada a lo largo de la investigación, señalando inicialmente que es el enfoque cualitativo el que sustenta la estructura general del trabajo, el cual "utiliza la recolección de datos sin medición numérica para descubrir o afinar preguntas de investigación en el proceso de interpretación" (Hernández, Fernández \& Baptista, 2010, p. 7). 
En cuanto al tipo de estudio, cabe señalar que se fundamenta en el método bibliográfico, descriptivo y explicativo, debido a que la investigación está orientada a estudiar la forma como se dinamizarán los mercados a partir de la entrada en vigencia del Protocolo de Madrid en el ámbito de la figura de la Franquicia en Colombia, partiendo del análisis de los referentes históricos, hasta determinar la dinámica actual con la introducción de normas sustanciales a nivel interno, dentro de las que se destacan no solo el Protocolo de Madrid sino el Tratado sobre el Derecho de Marcas (TLT) de la OMPI, declarado exequible por la Corte Constitucional en sentencia C- 261 de 2011.

El método bibliográfico se utiliza para conocer los enfoques y posturas que se han formulado desde la doctrina, siendo de vital importancia la revisión de la literatura a fin de detectar, consultar y obtener los documentos que sean útiles para el desarrollo del trabajo de investigación en su totalidad. La revisión de la literatura consiste en "detectar, consultar y obtener la bibliografía y otros materiales útiles para los propósitos del estudio, de los cuales se extrae y recopila información relevante y necesaria para el problema de investigación" (Hernández et. al, 2010, p. 53).

El método descriptivo se aplicará por cuanto se busca establecer las características y rasgos más importantes de los temas tratados en el estudio, siendo en este caso pertinente los tratados internacionales relacionados con el derecho de marcas y la propiedad industrial y la figura de la franquicia como mecanismo o herramienta válida para hacer valer tales derechos.

Finalmente, el método explicativo se utiliza porque permite estudiar las causas que originaron el fenómeno objeto de estudio, en este caso analizar los elementos constitutivos del contrato de franquicia, la estructura del Protocolo de Madrid y los efectos del mismo Tratado sobre el derecho de marcas. El estudio explicativo "va más allá de la descripción de conceptos o fenómenos o del establecimiento de relaciones entre conceptos; es decir, están dirigidos a responder por las causas de los eventos y fenómenos físicos o sociales" (Hernández et. al, 2010, p. 84).

\section{INTRODUCCIÓN}

El uso de las marcas y su registro requieren por parte del Estado colombiano acciones o políticas que permitan y faciliten el ingreso del empresariado colombiano al concierto internacional. Siendo entonces indispensable conocer la importancia que implica incorporar dentro del ordenamiento jurídico nacional herramientas que lo pongan en práctica.

En este sentido, la globalización ha marcado la posibilidad de incrementar el contexto comercial de las empresas y organizaciones comerciales, al posibilitar la expansión de los negocios nacionales en escenarios internacionales con la particularidad de que se establece la comunicación con los clientes on line, es decir, de forma inmediata, con lo cual la capacidad de negociar bienes y servicios debe contar con todas las herramientas jurídicas necesarias para desarrollarse a cabalidad de forma eficiente y eficaz.

Este es el paso fundamental que ha dado el Estado al aprobar, tardía pero necesariamente, el Protocolo de Madrid para el Registro Internacional de Marcas, quedando el escenario listo para que el empresario nacional y el internacional conozca cuáles son las nuevas reglas para el registro internacional de sus marcas, pero sobre todo, cuál es el nuevo marco legal que protege sus productos, respaldados ya no solo por la comunidad regional, representada en la Comisión de la Comunidad Andina, sino en la misma Organización Mundial de la Propiedad Intelectual (OMPI), organismo a través del cual se administra el Protocolo de Madrid.

Precisamente en este último punto se verifica la necesidad del presente estudio en cuanto a que el análisis jurídico del Protocolo de Madrid 
se convierte en un imperativo para entender y aplicar las ventajas que se obtienen de su aprobación en Colombia, tanto para los titulares de registros de marcas como para la economía nacional y el mismo Estado colombiano, máxime cuando ya existe una figura como las franquicias que facilitan la capacidad de los empresarios en explorar dichos mercados internacionales.

Dentro de las ventajas para los titulares de registros de marcas, manifestada en la exposición de motivos de la Ley 1455 (2011), aprobatoria del Protocolo de Madrid, se encuentra no tener que realizar el registro de marcas país por país, conforme se ha señalado en el Convenio de París de 1883: "Este sistema tradicional, muy pronto conoció sus propios límites, en particular por las dificultades que representa para un empresario el tener que presentar múltiples solicitudes en idiomas diferentes, el pago de tasas en monedas distintas, el manejo de procedimientos jurídicos diversos, entre otros" (Bermúdez \& Plata, 2011, p. 4).

Contrario sensu, a través del proceso de registro de marca que se lleva a través del Protocolo de Madrid, se supera el sistema tradicional de efectuar el registro de marcas país por país, para pasar a un proceso más expedito, el cual se inicia con el registro de marca en la Oficina nacional siendo, en el caso colombiano, la Superintendencia de Industria y Comercio (SIC), para luego iniciar un trámite en la Oficina Internacional para su Registro Internacional: "Basta con presentar, por medio de la Oficina nacional de propiedad industrial, una única solicitud (internacional) en un idioma, (...) y pagar un único conjunto de tasas en una única moneda (franco suizo). Se evita así tener que presentar solicitudes separadas en cada país en el que se desea obtener protección" (Bermúdez \& Plata, 2011, p. 6).

Para el Estado y la economía colombiana se prevé, será fundamental, pues los trámites serán menores al tener ya simplificada la protección de las marcas colombianas; contrario sensu, las empresas extranjeras tendrán igualmente las garantías para protección de sus marcas debidamente registradas y aprobadas con base en el mismo Protocolo de Madrid, tal como se ve a continuación.

\section{EL PROTOCOLO DE MADRID}

Mención especial tiene el análisis del Protocolo de Madrid, en cuanto a que fija una serie de herramientas jurídicas y procedimentales que permiten establecer un nuevo panorama tanto a los efectos del registro marcario como a la misma evolución de la franquicia en el marco de los negocios internacionales, consecuencia de las políticas aplicadas en los últimos gobiernos en donde la apertura económica, iniciada de forma activa por el gobierno Gaviria, ha sido el eje sobre el cual se construye el desarrollo del país, tal como lo expresa la Superintendencia de Industria y Comercio (SIC):

La economía colombiana se ha venido abriendo. Noticias relacionadas con colombianos haciendo empresa en otros países son frecuentes; el país ha mejorado en competitividad y las puertas para que sus productos se ofrezcan en otras latitudes se pretenden seguir abriendo a partir de tratados comerciales que el gobierno ha venido negociando con el apoyo del Congreso de la República (SIC, 2011, P.1).

Bajo este nuevo panorama, el Protocolo de Madrid refuerza el registro internacional de las marcas a través de procedimientos sencillos, rápidos y económicos, superando los innumerables problemas que representaba el registrar las marcas a nivel internacional. Esta facilidad se ve reflejada en el crecimiento notorio del registro de marcas, de manera que la OMPI (2011) reportó para el año 2010 un registro de marcas global de 3.664.576, cifra que en el 2000 era de 2.601.363. Por su parte, China es la responsable de casi la tercera parte de la primera cifra, en razón a que registró un total de un millón de marcas por año (ACPI, 2009, p. 1). 
Asimismo, es de anotar cómo en el artículo $2^{\circ}$ de dicho protocolo se indica la llamada "solicitud de base", que no es más que el inicio del proceso del registro internacional de la marca, tal como se comenta a continuación:

Cuando una solicitud de registro de una marca haya sido presentada en la Oficina de una Parte Contratante, o cuando una marca haya sido registrada en el registro de la Oficina de una Parte Contratante, el solicitante de esa solicitud (denominada en adelante "la solicitud de base") o el titular de ese registro (denominado en adelante "el registro de base"), sin perjuicio de lo dispuesto en el presente Protocolo, podrá asegurarse la protección de su marca en el territorio de las Partes Contratantes, obteniendo el registro de esa marca en el registro de la Oficina Internacional de la Organización Mundial de la Propiedad Intelectual (Protocolo de Madrid, 1989, art. $2^{\circ}$ ).

Tal como se puede inferir, al momento de ser registrada la marca en la oficina del país contratante (en este caso Colombia) y llevando un trámite sencillo de solicitud internacional, se obtiene una protección internacional, con la seguridad de que dicha marca registrada no será utilizada en otro país que sea miembro del Protocolo, aun cuando se debe precisar que la aprobación de la marca por parte de la Oficina Internacional debe estar sujeta a la extensión, y que la marca sea registrable en ese país. Vale precisar, igualmente, que cuando se habla de extensión de un registro internacional se hace referencia a la posibilidad de solicitar que los efectos del registro marcario puedan ser ampliados a jurisdicciones que no habían sido designadas en la solicitud inicial de registro.

Igualmente, el Protocolo ejusdem establece cómo el solicitante del registro debe indicar en forma pormenorizada los productos o servicios que cobijan dicho registro, sumado a las clases correspondientes establecidas en la clasificación del Arreglo de Niza. No obstante estos criterios, la Oficina Internacional será la encargada de verificar dicha clasificación para determinar su conformidad o inconformidad con dicho registro.

Ya en lo que tiene que ver con la substitución de un registro nacional o regional por un registro internacional, el artículo 4bis del Protocolo de Madrid establece que cuando "ambos registros están inscritos a nombre de la misma persona, se considerará que el registro internacional substituye al registro nacional o regional, sin perjuicio de los derechos adquiridos en virtud de este último" (Protocolo de Madrid, 1989, art. 4bis), pero con las siguientes condiciones:

- Que la protección que surja del registro internacional se extienda a la parte contratante, conforme lo señala el artículo $3^{\circ}$, relativo a las condiciones y resultados de las solicitudes de extensión territorial: deberá ser objeto de una mención especial en la solicitud internacional y la posibilidad de formularse con posterioridad al registro internacional.

- Que los productos y servicios que se encuentran enumerados en el registro nacional o regional se encuentren en igual forma numerados en el registro internacional.

- Que la extensión que se está realizando surta su efecto después de la fecha del registro nacional o regional.

Las ventajas de este procedimiento son evidentes, en la medida en que el marco de protección de la marca se extiende notablemente, pues pasa de ser nacional o regional para adquirir un carácter de protección internacional.

En lo concerniente a renovación del registro internacional, el Protocolo de Madrid ha establecido que el mismo se debe tramitar tan pronto expire el período de los 10 años, teniendo, sin embargo, un plazo de seis meses posteriores para que haga la respectiva renovación. Finalizado ese plazo de gracia, y si no se han hecho las respectivas renovaciones, automáticamente pierde el registro marcario internacional (Protocolo de Madrid, 1989, art. 7). 
Tal como se observa, el Protocolo de Madrid se convierte en una herramienta eficaz que permite la protección de las marcas a nivel internacional a través del Registro Marcario, lo que asegura a los empresarios contar con los mecanismos legales para hacer valer su propiedad industrial. En virtud al registro de marcas a nivel internacional analizado a través de este protocolo, se abordará enseguida el tema de las franquicias, como un instrumento jurídico que permite materializar los beneficios del Protocolo de Madrid, en tanto permite facilitar el comercio internacional, puesto que la transmisión de distintos elementos de propiedad intelectual es fundamental para su puesta en marcha.

\section{MARCO GENERAL DE LA FRANQUICIA}

Antes de entrar a analizar el marco teórico sobre el cual se sustenta el instituto de la franquicia, es necesario precisar algunos elementos conceptuales que permiten entenderlo con mayor precisión.

Conforme a lo señalado, el concepto de franquicia corresponde a la actividad comercial que "se lleva a efecto en virtud de un acuerdo o contrato por el que una empresa, denominada franquiciadora, ceda a otra, denominada franquiciada, el derecho a explotación de un sistema propio de comercialización de productos o servicios" (Mayorga, 2007, p. 1). Asimismo, la autora subraya que la franquicia está relacionada con la comercialización de bienes y servicios, en donde se deben incluir, como parte de su contenido, la cesión del uso de derechos relacionados con la propiedad industrial, la transmisión del saber hacer y la prestación de una asistencia técnica y/o comercial del franquiciador al franquiciado.

Para López (2008) el concepto se remonta a la Edad Media, más precisamente en Francia, donde se "otorgaban privilegios y autorizaciones en relación con servicios militares, recaudación de impuestos y derechos territoriales. Los soberanos necesitados de servicios y financiaciones recurrían a particulares, los cua- les tenían la obligación de entregar una parte de los importes obtenidos a sus soberanos" (López, 2008, p. 116). De este momento histórico es que surge la palabra franc que viene a significar el otorgamiento de un determinado privilegio por parte de un soberano a uno de sus súbditos en donde normalmente se refería a mercado, pesca o madera.

Para Giner (1991), citado por Mayorga (2007), en el contrato de franquicia están involucrados un franquiciador y una red de empresas que son las que integran la red franquiciada en donde se prevé la existencia de una serie de derechos que son puestos a los franquiciados, pero bajo la permanente vigilancia y control por parte del franquiciador, el cual está con el interés real de que el bien o servicio objeto del contrato mantengan el nivel y la calidad como si fuera el mismo franquiciador.

Como indica Mayorga (2007) la franquicia es un acuerdo por medio del cual el franquiciado y las empresas que hacen parte de la cadena de franquicias cooperan en la repartición de productos o servicios específicos, produciendo entonces una relación de identificación de las empresas que conforman el sistema de franquicia. Esta relación de cooperación e identificación empresarial equivale, de un lado, a que el franquiciador otorga a los franquiciados una gama de derechos de propiedad intelectual $e$ industrial y un método empresarial ensayado en el mercado y, de otro lado, en una acción de control bastante activa del franquiciador en referencia al desarrollo de las prestaciones que ofrece el público al franquiciado.

Desde otra perspectiva se señala cómo con el fenómeno de la globalización, iniciado en la segunda década del siglo XX, la irrupción de nuevos contratos de colaboración empresarial ha sido la característica en este último siglo. "Como consecuencia de estas modernas técnicas de marketing y distribución comercial apareció en el mundo del comercio el contrato de colaboración empresarial denominado franquicia o en inglés franchising" (López, 2008, p. 115). 
Por otro lado, son dos los factores que determinan la formalización de un contrato de franquicia: la transmisión de know - how y la cooperación comercial. En el primero se establece que es "un conjunto de conocimientos prácticos no patentado, derivados de la experiencia de un empresario, verificados por éste en la práctica, y relativos a la venta de producto o la prestación de servicios a los usuarios finales" (Ortega, 2009, p. 143). Además de estos dos elementos señalados por el autor, es preciso incluir el tema de la cesión o autorización para el uso de bienes inmateriales para su comercialización, llamado "paquete de franquicia" tal como lo menciona Lázaro (2000): "Este sistema propio de comercialización no puede ser otra cosa que un conjunto-orgánico- de derechos sobre bienes inmateriales susceptible de configurar una peculiar y exclusiva imagen de empresa, y que normalmente es referido con el apelativo de paquete de franquicia" (p. 96).

Dentro de este marco o conjunto de conocimientos está v. gr. la presentación de productos, las relaciones con la clientela, la gestión administrativa, etc. La cooperación comercial está determinada como la necesidad de "establecer una red de distribución con identidad común y mediante inversiones limitadas" (Ortega, 2009 , p. 143). Señala, igualmente, este autor como el éxito de este tipo de contratos obedece al desarrollo del vínculo que se establece entre las grandes multinacionales o grandes capitales y las pymes, que origina en su desarrollo la diversificación y el marketing de forma eficiente y eficaz, en la medida en que le permite a aquellas su expansión territorial y la conquista de mercados inexplorados y a estas el beneficio de poner todo su empeño en desarrollar la empresa.

Desde otra perspectiva, para Meyer (1992) la franquicia representa riesgos y beneficios dentro de los que se destacan: mal uso de la marca, reducción de la posibilidad de innovar y actuar libremente, la dificultad para identificar las empresas que constituyen la competencia directa del negocio, la monotonía, la menor independencia, ya que el concesionario debe seguir pa- trones del franquiciador, el apego a los manuales de operación del negocio, la considerable inversión inicial en el desarrollo del sistema de franquicia, pago de regalías y cuotas de publicidad. En cuanto a ventajas destaca, entre otras, la reputación, experiencia, asistencia técnica, gerencial y operacional, la motivación y la reducción del riesgo e incertidumbre.

Asimismo, este autor destaca la existencia de diferencias entre un contrato de franquicia $y$ un contrato de licencia de uso de cualquier signo distintivo e incluso de patentes. Este último tiene un contenido más restringido y limitado y se define como aquel acuerdo de voluntades a través del cual el titular del derecho (licenciante) otorga a otra persona natural o jurídica (licenciatario) un derecho limitado para producir, usar y vender el objeto licenciado mediante el pago de cánones o regalías. La licencia integra el objeto inmediato del contrato de franquicia pero no lo abarca en su totalidad. En un contrato de licencia, basta con que el licenciatario cumpla con los requerimientos de calidad que establezca el licenciante, la manera de operar y administrar el negocio, la reproducción idéntica de este no constituye objeto de interés entre las partes.

Otro de los aspectos que resaltan el contrato de franquicia es el relacionado con la Transferencia de Tecnología, que corresponde a un proceso mediante el cual los conocimientos sobre cómo producir bienes y servicios fluyen de quienes en cierto momento los tienen, a otros que lo requieren. Entendiéndose como tecnología el conocimiento sistemático para la manufactura de un producto, la aplicación de un proceso o la prestación de un servicio, ya sea que dicho conocimiento se refleje en una invención, un diseño industrial, un modelo utilitario, o una nueva variedad de fábrica; o en información o calificación técnica; o en los servicios de asistencia prestados por expertos para el diseño, instalación, operación o mantenimiento de una fábrica, o para la dirección de una empresa industrial o comercial o sus actividades, entonces se puede concluir que el contrato de franquicia es uno de los mecanismos de transferencias de 
tecnologías, ya que con la autorización para el uso del activo de propiedad intelectual, el titular transmite a la contraparte todo el know how para la operación del negocio, a través de la entrega de manuales técnicos que contienen todo el procedimiento de las operaciones de los sistemas, de los métodos de trabajos, hasta las directrices comerciales, entrenamiento permanente y verificación constante del cumplimiento de las condiciones pactadas en el contrato. (Dávalos, 1993).

En síntesis, se ha tratado de asimilar el Contrato de Franquicia a otras figuras jurídicas como las de distribución, agencia, de sociedad, cuando en realidad lo que sucede es que esta figura está compuesta por elementos combinados de cada uno de estos contratos, necesarios para garantizar el desarrollo armónico del negocio.

\section{Elementos del contrato de franquicia}

\section{- Franquiciador o franquiciante}

La característica del franquiciador está determinada por la obligación de ser que en él "se concentran o se deriva de la transmisión de la unidad patrimonial organizado o modelo de empresa que va a desarrollar el franquiciado [...] el franquiciador debe elaborar una particular fórmula comercial y poner a punto una serie de productos o servicios que serán objeto del sistema de afiliación" (Mayorga, 2007, p. 105). Bajo estas características es de suponer que el franquiciador dispone de un producto o servicio que ya ha sido mínimamente experimentado, en donde es clave la construcción de una red por parte del franquiciador que le permita al franquiciado orientar la comercialización de dichos bienes o servicios dentro del marco de criterios establecidos previamente por el franquiciador, quien tiene la responsabilidad de mantener de forma permanente $y$ constante la actualización de toda la estructura que se tiene montada.

De acuerdo con Pierre y Rebolledo (2003), el tema del franquiciador ha estado rondan- do dos intereses principalmente: por un lado, para obtener recursos y, por el otro, para solucionar de forma eficiente los mecanismos de control y motivación de los operadores. En la propuesta de la obtención de recursos, es claro que el franquiciador busca un crecimiento más rápido de los bienes o servicios que ofrece, siendo los franquiciados una punta de lanza para dicho crecimiento, en cuanto a que tienen los recursos necesarios para ello. La justificación está dada por la necesidad del franquiciador de mantener un control central sobre el franquiciado en tanto que está a la búsqueda de las economías de escala, el cubrimiento y la protección del mercado, inyección de recursos financieros y solución de problemas en manejo de recursos humanos y talento gerencial (capital intelectual).

En cuanto al segundo interés, solución de los mecanismos de control y motivación, buscan en la franquicia la descentralización y mayor crecimiento de los diferentes niveles organizacionales, permitiendo con ello que el poder del franquiciador esté orientado en el contrato, "el cual se manifiesta en la obligación de respetar las cláusulas contractuales y particularmente en la obligación de aplicar su sistema de explotación. El franquiciador conserva también un derecho de control del funcionamiento del negocio del franquiciado" (Pierre y Rebolledo, 2003, p. 64).

\section{- Franquiciado}

La determinación del franquiciado está determinada por la posición que tenga frente a los diferentes tipos de franquicias; de acuerdo con Mayorga (2007), el franquiciado es "la persona física o jurídica que explota en nombre propio la empresa franquiciad y que asume frente al franquiciador las obligaciones que se derivan del contrato de franquicias. Tiene, por tanto, la condición jurídica de empresario". Esta figura jurídica de empresario da a entender que tiene la autonomía e independencia frente al franquiciador, en cuanto a que se establece que es una relación contractual bilateral entre 
dos empresas, de ahí que sea preciso que los contratos que se establezcan tengan claras las reglas de juego que se establecen a fin de que el franquiciador no llegue incluso a afectar las operaciones administrativas desarrolladas por el franquiciado.

Además de estos dos elementos, Ortega (2009) determina que otros que hacen parte del mismo contrato de franquicia, en este caso internacional. En la tabla 1 se desarrolla cada uno de estos elementos conforme los ha propuesto este autor.

\subsection{Clases de contratos de franquicia}

De Miguel (1995) señala que en los contratos sobre bienes inmateriales -propiedad intelec- tual-, junto a la regulación jurídica del contrato propiamente dicho, prevalecen los intereses privados en donde también inciden normas configuradoras del sistema de protección y regulación de esos bienes inmateriales, las cuales son administradas y aplicadas por el Poder Público. Lo anterior, significa que una de las partes y a veces ambas, en lo que se refiere a la explotación pública de los bienes derivados de la propiedad intelectual, se deberán ajustar a las normas legales administrativas impuestas por el Estado para evitar, en todo lo posible, la utilización ilegal de esos bienes inmateriales. En este sentido se definen los diferentes tipos de contratos que han sido definidos conforme las normas establecidas por el Estado.

Tabla 1. Elementos del contrato de franquicia

\begin{tabular}{|c|c|}
\hline $\begin{array}{l}\text { ELEMENTOS DEL CONTRATO } \\
\text { DE FRANQUICIA }\end{array}$ & EXPLICACIÓN \\
\hline LICENCIA DE MARCA & $\begin{array}{l}\text { El franquiciador es el titular de la marca sobre un producto o servicio. } \\
\text { Derecho del franquiciado de utilizar sus signos y símbolos. }\end{array}$ \\
\hline TRANSFERENCIA DE KNOW HOW & $\begin{array}{l}\text { El franquiciador debe poner en práctica al franquiciado: conducción, } \\
\text { estructura y organización del negocio. }\end{array}$ \\
\hline REGALÍAS O CANON & $\begin{array}{l}\text { Establecimiento de alguna forma de retribución del fran-quiciado al } \\
\text { franquiciante. }\end{array}$ \\
\hline TERRITORIO & Delimitación de un área territorial en donde se desarrolla el contrato. \\
\hline $\begin{array}{l}\text { ASISTENCIA DEL FRANQUICIANTE } \\
\text { AL FRANQUICIADO }\end{array}$ & Establecido de forma clara, a través de un manual u otro medio. \\
\hline $\begin{array}{l}\text { LA NO COMPETEN CIA Y/O LAS } \\
\text { POSIBILIDADES DE SUBFRANQUICIAR }\end{array}$ & $\begin{array}{l}\text { El franquiciador está imposibilitado legalmente para establecer otro } \\
\text { tipo de negocios fijados en el contrato en el mismo territorio. }\end{array}$ \\
\hline CONFIDENCIALIDAD & $\begin{array}{l}\text { El franquiciado debe guardar celosamente la información que le sea } \\
\text { suministrada por el franquiciador o aquella que surja de la actividad } \\
\text { comercial. }\end{array}$ \\
\hline PLAZO DE DURACIÓN DEL CONTRATO & $\begin{array}{l}\text { Deben establecerse plazos razonables para que el franquiciado recu- } \\
\text { pere la inversión que tenga que hacer para aceptar la franquicia. (De } \\
2 \text { a } 5 \text { años). }\end{array}$ \\
\hline
\end{tabular}

Fuente: Ortega, 2009. 


\section{a) Contrato de transferencia tecnológica}

Se trata de un contrato por el que una persona física o jurídica proporciona a otra acceso a una tecnología o know-how a cambio de una remuneración. El know-how consiste en una serie de conocimientos técnicos, comerciales o de fabricación que tienen carácter secreto $y$ que proporcionan una ventaja a quien los utiliza en un proceso industrial.

En el caso colombiano, el Estatuto Tributario, en su artículo 207-2 numeral 8, establece una distinción tributaria para los procesos de transferencia tecnológica, la cual tiene como beneficio el tener rentas exentas: "Los nuevos productos medicinales y el software, elaborados en Colombia y amparados con nuevas patentes registradas ante la autoridad competente, siempre y cuando tengan un alto contenido de investigación científica y tecnológica nacional, certificado por Colciencias o quien haga sus veces, por un término de diez (10) años a partir de la vigencia de la presente ley" (Decreto 624 de 1989, art. 207-2).

\section{b) Contratos de know-how}

a. Contrato de know-how puro. Por medio del cual una empresa cede a otra la asistencia o conocimientos técnicos necesarios para el proceso de producción. En este caso, los conocimientos transferidos no son propiedad de quien los vende, sino que en principio dichos conocimientos pueden ser utilizados comercialmente por cualquier persona experta en la materia. Por otro lado, la empresa que transfiere la tecnología suele comprometerse a no cederla a terceras partes en el territorio en que se haya concedido en exclusiva, ni tampoco a explotar dicha tecnología directamente. Es el denominado pacto de exclusividad.

b. Contrato de know-how mixto. De acuerdo con el ICEX (s.f.) este tipo de contratos se desarrolla cuando una empresa cede no solamente la transmisión de tecnología sino también la utilización de bienes inmateriales como las patentes, las marcas, los rótulos y los nombres comerciales, entre otros. "En estos casos, quien transfiere los conocimientos tiene un derecho exclusivo de propiedad sobre ellos, es decir, que es titular de un derecho de patente sobre dichos conocimientos. Es lo que se denomina tecnología patentada" (p. 1).

De acuerdo con Morejon (2008), es necesario distinguir la franquicia del contrato de distribución de bienes, pues si bien este puede tener niveles altos de distribución del negocio de quien es el titular de los bienes, cabe resaltar que este tipo de contratos no conlleva la transmisión de derechos sobre la propiedad industrial, llamado know how: "Normalmente, éste se limita a suministrar productos portadores de la marca, quedando el distribuidor habilitado para comercializarlo con los signos del suministrador, sin necesidad de una autorización, por haber agotado el titular su derecho con la introducción del bien en el mercado. Por tanto, la distribución puede ser parte del contrato de franquicia, pero no su fin último" (p. 21).

Esta situación sucede, igualmente, con el contrato de agencia, pues pese a tener características similares, como la duración y la celebración por empresarios mercantiles, el objeto de este tipo de contratos está en la promoción o conclusión de otros contratos: "El agente es un promotor de operaciones que influye en la voluntad de terceros para convencerlos de suscribir contratos en interés de su representado y aunque en ocasiones participe de alguna manera en la ejecución del contrato no se dedica a la misma actividad comercial que su representado, su tarea es la promoción y suscripción de los contratos del giro de que se trate, su representado lo ejecutará" (Morejón, 2008, p. 21).

De igual forma, este autor destaca una determinada analogía entre la franquicia y el contrato de sociedad, en tanto ambos buscan que el negocio termine en una exitosa operación señalando, inclusive, cómo teóricamente tienen similitudes, pero que, en la práctica, se presen- 
tan diferencias en cuanto a que la franquicia no se crea una empresa con personalidad jurídica propia sino que se basa en las relaciones de cooperación, colaboración, ayuda y asistencia entre dos empresas que guardan, cada una, su independencia y autonomía (Morejón, 2008).

\section{Clasificación de las franquicias}

Para Pierre y Rebolledo (2003) existen tres tipologías de franquicia, las cuales tienen a su vez una serie de categorías que las hacen viables, tal como se especifican en la Tabla 2.

Tabla 2. Tipologías de franquicia

\begin{tabular}{|c|c|c|}
\hline $\begin{array}{c}\text { TIPOLOGÍAS } \\
\text { DE FRANQUICIA }\end{array}$ & CATEGORÍAS & EXPLICACIÓN \\
\hline \multirow[t]{3}{*}{$\begin{array}{l}\text { Según el papel des- } \\
\text { empeñado por los } \\
\text { participantes en el } \\
\text { canal de producción. }\end{array}$} & $\begin{array}{l}\text { Franquicia productor-mino- } \\
\text { rista, el cual se utiliza en ser- } \\
\text { vicios y productos de muy } \\
\text { corta duración. }\end{array}$ & $\begin{array}{l}\text { El productor es franquiciador y el minorista es franquiciado. Este } \\
\text { ofrece el producto a consumidores conforme las estipulaciones co- } \\
\text { merciales del contrato. } \\
\text { El franquiciador guarda el control sobre la calidad de los productos } \\
\text { y los servicios que se ofrecen, en donde este salva la uniformidad de } \\
\text { la politica comercial que tenga establecida. }\end{array}$ \\
\hline & $\begin{array}{l}\text { Franquicia Productor- Mayo- } \\
\text { rista. Utilizado generalmente } \\
\text { por empresas de productos } \\
\text { tangibles (v. gr. Coca - Cola). }\end{array}$ & $\begin{array}{l}\text { El productor es franquiciador y el mayorista es franquiciado. El pro- } \\
\text { ductor tiene la capacidad de control sobre el canal de distribución, } \\
\text { además de manejar aspectos muy especíicos como el apoyo co- } \\
\text { mercial, el cual es manejado de igual forma por otros franquiciados. }\end{array}$ \\
\hline & $\begin{array}{l}\text { Franquicia Mayorista - Mino- } \\
\text { rista (v. gr. algunas estaciones } \\
\text { de servicio. }\end{array}$ & $\begin{array}{l}\text { El mayorista es franquiciador y el minorista es franquiciado. El pri- } \\
\text { mero opera como central de compras no involucrando directamen- } \\
\text { te a los productores. }\end{array}$ \\
\hline \multirow[t]{3}{*}{$\begin{array}{l}\text { Franquicia según la } \\
\text { actividad del franqui- } \\
\text { ciador }\end{array}$} & Franquicia de producción. & $\begin{array}{l}\text { El franquiciador ofrece una serie de productos, en tanto que el fran- } \\
\text { quiciado se encarga de su comercialización. También se le llama } \\
\text { franquicia de marca, es decir, que permite que el franquiciado utilice } \\
\text { la marca en el comercio. }\end{array}$ \\
\hline & $\begin{array}{l}\text { Franquicia de servicio o de ex- } \\
\text { plotación }\end{array}$ & $\begin{array}{l}\text { El franquiciador ofrece un servicio particular estandarizado a los } \\
\text { consumidores y construye una marca comercial; el franquiciado asu- } \\
\text { me el sistema de servicio propuesto, lo que implica un seguimiento } \\
\text { y control por el franquiciador. }\end{array}$ \\
\hline & Franquicia de distribución. & $\begin{array}{l}\text { El franquiciador (mayorista o minorista) hace una propuesta al fran- } \\
\text { quiciado para el manejo de una selección muy específica de produc- } \\
\text { tos de diferentes marcas, en donde el franquiciador tiene el control } \\
\text { de aspectos muy claves en la comercialización como: inventarios, } \\
\text { sistemas de gestión y publicidad principalmente. }\end{array}$ \\
\hline \multirow{3}{*}{$\begin{array}{l}\text { Franquicia según el } \\
\text { grado de libertad del } \\
\text { franquiciado }\end{array}$} & Franquicia individual & $\begin{array}{l}\text { El franquiciado tiene el derecho a explotar de forma exclusiva un } \\
\text { establecimiento en un sitio muy específico. El franquiciador controla } \\
\text { la expansión de la red y la limitación de las mismas franquicias. }\end{array}$ \\
\hline & Franquicia múltiple & $\begin{array}{l}\text { El franquiciado tiene el derecho a explotar una zona específica, pero } \\
\text { con la posibilidad de tener varios puntos de venta, teniendo con } \\
\text { ello mayores posibilidades de crecimiento. El franquiciador controla } \\
\text { igualmente el territorio o la zona que se dispuso. }\end{array}$ \\
\hline & Franquicia maestra & $\begin{array}{l}\text { El franquiciado tiene el derecho de explotar no solo establecimien- } \\
\text { tos propios sino que tiene la posibilidad de subcontratar la franquicia } \\
\text { con otros franquiciados. El franquiciador asesora de forma directa } \\
\text { los establecimientos propios, dejando el margen de manejo de los } \\
\text { demás al franquiciado. }\end{array}$ \\
\hline
\end{tabular}

Fuente: elaboración propia del autor. 
Desde otra perspectiva, para la Asociación Mexicana de Franquicias (AMF) (2002) existen diferentes tipos de franquicias que se pueden encontrar en el entorno del mercado mundial, así:

1. Franquicia de formato de negocio. Mediante la cual se transfieren los elementos tecnológicos además de que el franquiciante presta una asistencia técnica continua.

2. Franquicia de distribución exclusiva. El valor agregado de esta clase de franquicia radica en la producción de artículos o productos originales como factor relevante del negocio.

3. Franquicia de producto y marca. En esta clase de franquicia el producto y el valor de la marca hacen el conjunto del éxito en el negocio.

Por otro lado, diversas categorías podemos encontrar en los diferentes tipos de franquicias anteriormente mencionados, entre las que se encuentran (Guzmán,2003):

Franquicia Individual. Es la que se otorga a una persona con un solo contrato específico.

Franquicia Múltiple. Se otorga a una persona a la que se le asigna un territorio para que venda unidades durante un tiempo establecido.

Franquicia Regional. Se concede a una persona para que difunda una franquicia en una zona determinada.

Franquicia Maestra Internacional. Aquí el franquiciante traslada una franquicia de un país a otro para que pueda ser explotada y utilizada en todo un territorio.

Teniendo definida la franquicia como un elemento en el cual se dinamiza y materializa el Protocolo de Madrid, a continuación se aborda el marco jurídico en el cual se inscriben las marcas, como un instrumento jurídico que permite a las empresas hacer valer su derecho, bien a través de las franquicias o a través de los mecanismos establecidos por el Protocolo de Madrid, de ahí que sea preciso desarrollar el marco jurídico sobre el cual se inscriben las marcas.

\section{MARCO JURÍDICO DE LAS MARCAS}

El tema de las marcas podría considerarse que ha cobrado importancia e interés desde la aparición del fenómeno de la globalización, ya que ha originado un desarrollo del concepto de marca y su legitimación dentro del derecho internacional y las legislaciones internas de cada uno de los países que participan en el comercio internacional de bienes y servicios.

La Comunidad Andina de Naciones (CAN), a través de la Comisión (2000), aprobó el "Régimen Común sobre Propiedad Industrial" mediante la Decisión 486. Esta normatividad define la marca en su artículo 134 como "cualquier signo que sea apto para distinguir productos o servicios en el mercado. Podrán registrarse como marcas los signos susceptibles de representación gráfica. La naturaleza del producto o servicio al cual se ha de aplicar una marca en ningún caso será obstáculo para su registro". A renglón seguido señala los signos por los cuales se pueden constituir marcas: palabras o combinación de palabras; imágenes, figuras, símbolos, gráficos, logotipos, monogramas, retratos, etiquetas, emblemas y escudos; los sonidos y los olores; las letras y los números; un color delimitado por una forma o una combinación de colores; la forma de los productos, sus envases o envolturas y cualquier combinación de los signos indicados en los apartados anteriores.

Para el Ministerio de Comercio, Industria y Turismo (Mincomercio) y la Superintendencia de Industria y Comercio, la marca, desde un punto de vista mercantil o comercial, es "un signo distintivo que sirve para identificar productos o servicios en el mercado. Es el signo que otorgará a una persona y/o empresa la capacidad de identificar sus productos o servicios de otros idénticos o similares" (SIC, 
2008, p. 13). Se destaca, en esta definición, dos elementos constitutivos de la marca: identificación y signo; la identificación corresponde a la forma como quieren los empresarios que se equipare el producto frente a otros y, el signo ya hace referencia a la forma que tendrá en el producto. Estas entidades señalan, igualmente, como las marcas "pueden consistir en palabras, letras, números, dibujos, imágenes, formas, colores, logotipos, figuras, símbolos, gráficos, monogramas, retratos, etiquetas, emblemas, escudos, sonidos o combinación de estos elementos" (Mincomercio, 2008, p. 13).

Desde otra óptica se señala que la marca tiene tanta trascendencia que estampa su sello en el bien o servicio. "De allí entonces la denominación de marca a todo aquello que identifique a un bien o servicio ofrecido por un exportador (vendedor). Va tan estrechamente relacionado a la mercancía que puede, incluso, utilizarse la misma marca en otros productos siempre y cuando sean de naturaleza diferente" (Sierralta, 2004, p. 412).

Bajo esta conceptualización, se pretende señalar cómo las marcas tienen por objeto informar a los consumidores sobre los productos que pueden comprar para satisfacer sus necesidades, sobre la base de que la marca le garantiza la calidad o el servicio esperado, v.gr. la marca "Arturo Calle" que ofrece una completa línea de productos como zapatos, vestidos, camisas, medias, sacos, etc., lo que permite una identificación del cliente con estas líneas completas, las cuales no tiene ningún otro competidor con su marca.

En síntesis, lo que se busca con las marcas es que tengan la capacidad de distinguir un producto o servicio entre otros de igual o similar característica, de ahí que si no se cumple este fin, de hecho no será una marca. Asimismo, se destaca cómo al ser incorporada y registrada por la empresa, pasa a ser parte del patrimonio de la misma, de forma independiente así la marca tenga la misma denominación de la compañía. En este sentido, en la Tabla 3 se muestra los diversos tipos de marcas presentes en la legislación internacional.

Tabla 3. Tipos de Marca

\begin{tabular}{|l|l|l|}
\hline \multicolumn{1}{|c|}{$\begin{array}{c}\text { Forma } \\
\text { del Signo }\end{array}$} & \multicolumn{1}{|c|}{$\begin{array}{c}\text { Función } \\
\text { del Signo }\end{array}$} & \multicolumn{1}{c|}{$\begin{array}{c}\text { Uso } \\
\text { y Difusión }\end{array}$} \\
\hline Nominativas & Comerciales & Comunes \\
\hline Figurativas & Colectivas & Notorias \\
\hline Mixta & De certificación & Renombradas \\
\hline Tridimensionales & & \\
\hline Sonoras & & \\
\hline
\end{tabular}

Fuente: Mincomercio, 2008, p. 16

Por otro lado, para la OMPI (1994), la característica principal de las marcas es que correspondan a signos visibles, incluyendo con esto las marcas tridimensionales, pero excluyendo los hologramas y las marcas sonoras y olfativas. No obstante, esta agencia especializada de las Naciones Unidas no tiene una definición exacta de lo que significan las marcas, sino que establece los criterios para su protección en el ámbito de los países que se han adherido al Protocolo de Madrid, que es el instrumento internacional que normativiza lo relacionado con las marcas, en especial el Registro Internacional de Marcas.

Desde otra perspectiva, se define la marca como un signo: "una realidad intangible que para su percepción debe dotarse de forma sensible, materializándose en el producto, envase o en objetos utilizados en la prestación de servicios. Acorde a la moderna tendencia instaurada en el Derecho comparado, en el concepto de signo ha de englobarse cualquier representación que evoque una cosa, resultando omnicomprensivo de las más diversas estructuras o composiciones que puedan ser reconocidas como marca por el público consumidor" (Chijane, 2007, p. 28). De esta definición se concluye que la marca tiene sentido en tanto se encuentre un signo y un producto (bien o servicio) designado. 
Este autor señala, además, que la marca tiene la característica de ser autónoma e independiente del mismo producto, pero que su fin sí es la identificación de determinado bien o servicio, con lo cual se establece una distinción con otros bienes o servicios de las mismas características y funciones. "Por lo indicado, todas las legislaciones coinciden en dos puntos: a) concebir estructuralmente a la marca como un signo, y b) resaltar funcionalmente sus fallidas distintivas. No cualquier signo gozará de protección jurídica, sino aquel que posea aptitud para identificar y distinguir las diversas prestaciones empresariales ofertadas en el mercado" (Chijane, 2007, p. 29).

Para Sierralta (2004) la marca tiene una serie de funciones tal como se muestra en la Tabla 4.

Tabla 4. Funciones de la marca

\begin{tabular}{|l|l|}
\hline FUNCIONES & \multicolumn{1}{|c|}{ CARACTERÍSTICA } \\
\hline Distintiva & $\begin{array}{l}\text { Con las marcas se singulariza e identi- } \\
\text { fican los bienes y servicios que circulan } \\
\text { por el mundo o por algunas regiones, } \\
\text { como un signo distintivo para los con- } \\
\text { sumidores de lo que están comprando } \\
\text { dando, con ello, una determinada per- } \\
\text { sonalidad a los productos. }\end{array}$ \\
\hline Mercadológica & $\begin{array}{l}\text { Coadyuva a segmentar el mercado en } \\
\text { algunos casos, y en otros a discrimi- } \\
\text { nar los precios conforme el nivel de } \\
\text { posicionamiento de la marca. }\end{array}$ \\
\hline Homogeneidad & $\begin{array}{l}\text { Permite que los consumidores tengan } \\
\text { la certeza de que el producto adquiri- } \\
\text { do en una marca determinada tiene } \\
\text { las condiciones de calidad, indepen- } \\
\text { dientemente del sitio donde se comer- } \\
\text { cialice. }\end{array}$ \\
\hline $\begin{array}{l}\text { Garantía } \\
\text { de calidad }\end{array}$ & $\begin{array}{l}\text { Estas condiciones señaladas dan una } \\
\text { garantía de calidad en caso de encon- } \\
\text { trarse fallas en su elaboración v. gr. } \\
\text { la marca de móviles: Sony, Samsung, } \\
\text { Nokia, etc. }\end{array}$ \\
\hline Indicadora \\
de Origen & $\begin{array}{l}\text { Pese a que la confección de muchos } \\
\text { productos tiene diverso origen en sus } \\
\text { partes, no obstante el usuario o clien- } \\
\text { te identifica la marca con un origen } \\
\text { específico. }\end{array}$ \\
\hline
\end{tabular}

Fuente: Sierralta (2004)
Pese a no ser estos elementos señalados en la Tabla 1 como constitutivos de la marca desde un punto de vista jurídico, son esenciales para poder comprender la trascendencia legal de la misma.

Ya en el terreno jurídico, el Consejo de Estado de Colombia (2009), señala cómo las marcas tienen su trascendencia jurídica a partir del registro de la misma "porque a partir del registro se legitima al titular de la marca para identificar con ella todos sus productos y servicios en el mercado, sin que sea posible la variación de los elementos que la integran de forma que la alteren. Además, tiene derecho al uso indirecto de la marca lo que significa que el titular puede dar, incluso durante el trámite del registro, licencia a uno o más terceros para la explotación de la misma". Señala, igualmente, cómo este último aspecto se materializa a través de los contratos de licencia de uso en donde se pactan a título oneroso o gratuito $y$ de forma exclusiva si se estipula, en donde, en éste último caso, el titular renuncia al derecho que tiene por la explotación de la marca, sumado al hecho de poder iniciar acciones jurídicas contra terceros que utilicen la marca $y$, con ello, afectar al titular de derecho.

Asimismo, el Consejo de Estado (2009) señala como las marcas son un activo intangible de las compañías, lo que puede llegar a constituirse, inclusive, en algo de mayor valor que los mismos bienes tangibles v. gr. Coca - Cola. Expresa, igualmente, citando a la Superintendencia de Industria y Comercio como las marcas tienen "gran valor como mecanismo de información, como mecanismo de publicidad y como herramienta de competencia, en la medida en que permiten canalizar la clientela. Esas características repercuten en que la marca sea un intangible que puede agregarle valor a una empresa, dándole herramientas de competitividad, aumentado el valor de los activos y facilitando sus transacciones comerciales".

Bajo estas características, el registro de la marca genera o deriva en unos derechos como la 
titularidad de la marca, el derecho de uso, derecho al uso indirecto de la marca y el derecho de disposición, principalmente. El derecho a la titularidad de la marca se encuentra establecido por el hecho de que el registro de marca da la propiedad industrial con la cual se encuentra legalmente autorizado para la explotación de la marca, conforme a las características señaladas en el mismo registro.

En cuanto al derecho al uso, en el Artículo 154 de la Decisión 486 de 2000 establece cómo "el derecho al uso exclusivo de una marca se adquirirá por el registro de la misma ante la respectiva oficina nacional competente". Conforme lo señala el Consejo de Estado (2009), con el derecho de uso se está legitimando al titular de la marca para que identifique los productos y servicios que estarán en el mercado, protegiendo, con ello, la posible variación de los elementos constitutivos señalados en el registro como tal.

En lo que concierne al derecho del uso indirecto de la marca, es preciso subrayar que el artículo 162 de la Decisión 486 de 2000 fue modificado por el artículo $5^{\circ}$ del Decreto 729 de 2012, al señalar que las licencias de uso de marcas serán opcionales, lo que implica que "la ausencia de dicho registro no afectará la validez u oponibilidad de tales contratos" (Decreto 729 , art. $5^{\circ}$ ). Esta nueva normativa define un cambio sustancial, en tanto en el artículo 162 mencionado establecía la obligatoriedad del registro de dicha licencia. Asimismo, el Consejo de Estado se ha pronunciado sobre las características de las licencia.

El derecho en mención se materializa con los contratos de licencia de uso que se pactan a título oneroso o gratuito. Estas licencias pueden otorgarse de manera exclusiva, es decir, que el titular renuncia a su derecho de conceder otras licencias sobre el mismo signo o también puede concederse la licencia no exclusiva donde el titular podría otorgar varias y simultáneas autorizaciones para el uso de la misma a diferentes personas naturales o jurídicas (Consejo de Estado, Sala de lo Contencioso Administrativo, 2009, Sentencia 00739).

En cuanto al derecho de disposición en el registro de marca cabe señalar que le permite al titular vender, transferir o ceder todas las dispensas que se derivan de la marca a terceros, siempre y cuando se inscriba el contrato ante la Superintendencia de Industria y Comercio, de lo contrario no surtirá efecto alguno. Asimismo, esta entidad se encuentra en capacidad de reconocer a determinadas marcas la notoriedad de las mismas, las cuales le dan un mayor nivel de salvaguardia: protección más amplia abarcando inclusive otros productos que no se encuentren protegidos de forma expresa; protección extraterritorial y comparación de los signos cuando se encuentre o alegue confusión en los mismos.

\section{CONCLUSIONES}

Para entender los efectos que tiene la aprobación en Colombia del Protocolo de Madrid, es necesario pensar y comprender el panorama jurídico sobre el cual se sustenta la aprobación y sus efectos económicos, especialmente en el derecho de marcas y en el contrato de franquicia.

La franquicia es, como se vio, un mecanismo jurídico, comercial, que permite o abre las posibilidades para el uso y explotación de una marca, representada en bienes o servicios que podrán ser explotados por la empresa franquiciada, lo que implica el derecho al uso de la propiedad industrial que se ha cedido en los términos establecidos en el contrato.

Dada su importancia en el marco del comercio internacional, el instituto de la franquicia se convierte en un escenario idóneo y propicio para que el franquiciador pueda extender la capacidad de comercialización de sus productos del cual es propietario pero que, bajo dichos intereses, cede parte de sus derechos para lograr un mayor posicionamiento en el mercado. 
De igual forma, se debe resaltar la necesidad de hacer un mayor estudio sobre la institución de la franquicia, puesto que con el Protocolo de Madrid se podría dar una proliferación del registro de marcas, las cuales son mayormente utilizadas a través de contratos de franquicia. En otras palabras, este estudio del contrato de franquicia debe realizarse en aras de procurar una armonía con el protocolo de Madrid, siendo necesario la articulación de este con entidades como la Superintendencia de Industria y Comercio y del Ministerio de las Tecnologías de la Información y las Comunicaciones.

En el caso del instituto de marcas, como eje jurídico-comercial, se aprecia que es un reto para el derecho interno, sobre todo para el legislador, quien debe ajustar la normatividad a las regulaciones internacionales; la omisión de estos ajustes afectarían al productor colombiano, el cual se vería sometido a la fortaleza marcaria de los países industrializados, siendo entonces estos cambios esenciales para crear una mejor y eficaz seguridad jurídica de que sus productos no serán utilizados en otros países aprovechando la inocua normatividad colombiana.

En este punto se ubica el Protocolo de Madrid como uno de los principales instrumentos jurídicos de protección de la propiedad industrial, en cuanto a que permite que el registro de marcas establecido en el país de origen, en este caso Colombia, tenga efectos internacionales de protección, con lo cual el empresario colombiano no se ve sometido a complejos procedimientos en oficinas internacionales de registro de marcas, en donde los costos para su aprobación son muy altos.

Esta necesidad obedece al inusitado crecimiento en el registro de marcas a nivel internacional, siendo un indicativo claro de la importancia que tiene registrar la propiedad industrial. Con la inclusión en la normativa interna, el Protocolo de Madrid es un fuerte incentivo para entrar a competir en el naciente mercado latinoamericano de registro de marcas, en donde Brasil y Argentina desempeñan actualmente un papel protagónico, pues tienen 2,33 y 4,65 patentes por millón de habitantes, respectivamente (Rivera, 2009, p. 55).

El Protocolo de Madrid abre, entonces, las opciones para que inversionistas nacionales y extranjeros adquieran derechos de comercialización más seguros, siendo la franquicia una figura jurídica idónea para hacerla efectiva en cualquiera de los países en donde tenga validez dicho Protocolo.

Finalmente, se debe señalar cómo la reciente Ley 1455 de 2011, relativa a la adhesión de Colombia al Protocolo de Madrid, invita necesariamente a hacer un análisis de los fundamentos constitucionales y legales sobre los cuales se soporta para su ratificación dentro del marco legal nacional.

Esto trae, como consecuencia, la necesidad de relacionar los efectos o cambios que ocurren en el manejo o procedimiento relacionado con el Registro Internacional de Marcas, los efectos a los titulares de una marca o a quienes deseen crear o utilizar una marca bajo la figura de la franquicia. Prima facie el Protocolo de Madrid genera una nueva dinámica, donde ya entra en juego lo que se ha venido manejando en el sistema internacional de marcas, de la cual la OMPI tiene el liderazgo en este escenario. Estas consideraciones impulsan la necesidad de generar un nuevo trabajo que analice de forma sistemática el Protocolo de Madrid y los efectos de su adhesión en el entorno nacional, siempre en el marco de su constitucionalidad y viabilidad en un país como Colombia, en proceso de desarrollo.

\section{REFERENCIAS}

Asociación Mexicana de Franquicias (2002). ¿En dónde Nació el Sistema de Franquicias? Extraído Agosto 12, 2012, desde http:// www.franquiciasdemexico.org/index-htm.htm Bermúdez, J \& Plata, L. (2011). Exposición 
de Motivos Ley 1455 de 2011. Congreso de la República de Colombia. Bogotá D. C.

Chijane, D. (2007) Derecho de marcas. Madrid: Editorial Reus S.A.

Corte Constitucional de Colombia. Sentencia C-251 de 2012 (MP. Humberto Antonio Sierra Porto; Marzo 28 de 2012).

Consejo de Estado de Colombia. Sala Plena de lo Contencioso Administrativo. Sentencia 00739 de 2009 (MP. Mauricio Torres Cuervo; Marzo 24 de 2009).

Convenio de París para la Protección de la Propiedad Industrial. (1883). Extraído Agosto 13, 2012, desde http://www.wipo.int/treaties/ip/paris/index-es.html

Dávalos, R. (1993). Las Empresas Mixtas, Regulación Jurídica. Segunda Edición. España: Editorial Mateu Cromo.

Decisión 486 de 2000. Régimen Común sobre Propiedad Industrial. 14 de Septiembre de 2000. Gaceta Oficial del Acuerdo de Cartagena $N^{\circ} 600$ de 19 de Septiembre de 2000.

Decreto 624 de 1989. Por el cual se expide el Estatuto Tributario de los Impuestos Administrados por la Dirección General de Impuestos Nacionales. Marzo 30 de 1989. DO. $\mathrm{N}^{\circ}$ 38.756.

Decreto 0729 de 2012. Por el cual se reglamentan parcialmente las Decisiones 486 y 689 de la Comisión de la Comunidad Andina. Abril 13 de 2012. DO. N 48.400 .

De Miguel, P. (1995). Contratos Internacionales sobre Propiedad Industrial. Madrid: Editorial Civitas.

Hernández, Fernández-Collado \& Baptista (2008). Metodología de la Investigación. México: Editorial Mc Graw Hill.
ICEX España Exportación e Inversiones (s.f.). Contrato de transferencia tecnológica. Extraído Agosto 13, 2012 desde http://www. icex.es/icex/cma/contentTypes/common/ records/mostrarDocumento/?doc=604750.

Lázaro, E. (2000). El Contrato de Franquicia, Aspectos Básicos. España: Ediciones de la Universidad de Murcia.

Ley 1455 de 2011. Por la cual se aprueba el Protocolo concerniente al arreglo de Madrid relativo al Registro Internacional de Marcas. Junio 19 de 2011. DO. N 48.116.

López, F. (2008). El Contrato de Franquicia Internacional. Bogotá D. C.: Ediciones Jurídicas Gustavo Ibáñez.

Mayorga, M. (2007). El contrato mercantil de franquicia. Segunda Edición. Granada: Editorial Comares.

Meyer, H. \& Kohns, S. (1992). Marketing, Ventas al por menor. Bogotá D.C.: Editorial McGraw-Hill.

Morejón, A. (2008). El contrato de franquicia. Cienfuegos: Universidad de Cienfuegos. Extraído Agosto 14, 2012, desde http:// www.eumed.net/libros-gratis/2009a/478/ EL\%20CONTRATO\%20DE\%20FRANQUICIA\%20NATURALEZA\%20JURIDICA.htm.

Organización Mundial de la Propiedad Intelectual OMPI. (2011). World Intellectual Property indicators WIPO Economic \& Statistics Series. Extraído Agosto 3, 2012, desde http://www.wipo.int/export/sites/www/ freepublications/en/intproperty/941/wipo_ pub_941_2011.pdf

Organización Mundial de la Propiedad Intelectual OMPI. (1994). Tratado sobre el Derecho de Marcas. Extraído 1 Agosto, 2012. Desde: http://www.wipo.int/treaties/es/ip/ tlt/trtdocs_wo027.html 
Ortega, A. (2009). Guía práctica de Contratación Internacional. Madrid: ESIC Editorial. Pierre, S. \& Rebolledo, C. La Franquicia en Colombia, Grupo Editorial Norma, Bogotá. 2003.

Protocolo de Madrid Concerniente al Arreglo de Madrid Relativo al Registro Internacional de Marcas. Artículos 2,3, 4 bis, 7. 27 de junio de 1989.

Rivera, J. (2009). Una propuesta de innovación del sistema de registro de marcas y patentes en Colombia. Medellín (Antioquia), Colombia: Universidad Nacional de Colombia. Sierralta, A. (2004). Contratación Internacional de marcas, patentes y Know-how. Revista
Universitas 107, p. 404-449. Pontificia Universidad Javeriana.

Superintendencia de Industria y Comercio de Colombia (SIC) (2011). Protocolo de Madrid: una herramienta para facilitar la presencia de marcas colombianas en el exterior. Bogotá D. C.

UNIDROIT. Instituto Internacional para la Unificación de Derecho Privado. (2005). Guía para los acuerdos de franquicia principal internacional. Extraído Agosto 3, 2012, desde http://www.unidroit.org/spanish/ guides/1998franchising/franchising-guide-s. pdf 